\title{
A Randomized, Controlled Trial of Prednisone Plus Cyclophosphamide in Patients with Advanced-stage IgA Nephropathy
}

\section{Zhonglin Feng}

Guangdong Provincial People's Hospital

\section{Ting Zhong}

Guangdong Provincial People's Hospital

\section{Li Song}

Guangdong Provincial People's Hospital

\section{Wei Shi}

Guangdong Provincial People's Hospital

\section{Yiming Tao}

Guangdong Provincial People's Hospital

\section{Zhiming Ye}

Guangdong-Hong Kong Joint Laboratory on Immunological and Genetic Kidney Diseases

Shuangxin Liu

Guangdong Provincial People's Hospital

\section{Zhiyong Xie}

Southern Medical University

\section{Zhilian Li}

Guangdong Provincial People's Hospital

\section{Yuanhan Chen}

Guangdong Provincial People's Hospital

\section{Ruizhao Li}

Guangdong Provincial People's Hospital

\section{Li Zhang}

Guangdong Provincial People's Hospital

\section{Wenjian Wang}

Guangdong Provincial People's Hospital

\section{Lixia Xu}

Guangdong Provincial People's Hospital Jianchao Ma

Guangdong Provincial People's Hospital Huaban Liang 
Guangdong Provincial People's Hospital

\section{Wei Dong}

Guangdong Provincial People's Hospital

Xinling Liang ( $\nabla$ xinlingliang_ggh@163.com )

Guangdong Provincial People's Hospital

\section{Research Article}

Keywords: IgA Nephropathy, Cyclophosphamide, Prednisone, randomized controlled trial

Posted Date: December 8th, 2021

DOI: https://doi.org/10.21203/rs.3.rs-923557/v1

License: (c) (i) This work is licensed under a Creative Commons Attribution 4.0 International License. Read Full License 


\section{Abstract}

\section{Background}

Treatments with glucocorticoids or immunosuppressants in IgA nephropathy remain controversial, especially in IgA nephropathy patients with renal insufficiency and small quantities of proteinuria. So far, no randomized controlled study has investigated whether cyclophosphamide has a protective effect on IgA nephropathy independent of glucocorticoids.

\section{Methods}

We conducted a single-center, randomized, controlled trial ((NCT01758120)). 135 IgA nephropathy patients with elevated plasma creatinine concentrations $(1.3-3.0 \mathrm{mg} / \mathrm{dl}$ in males and 1.0-3.0 mg/dl in females), regardless of proteinuria level, were enrolled in and randomized 1:1 to the prednisone alone group or prednisone plus cyclophosphamide group. The daily dosage of oral prednisone was initiated at $0.5 \mathrm{mg} / \mathrm{kg} / \mathrm{d}$ taken every morning for 2 months and then tapered by $20 \%$ each month for the next 4 months in prednisone alone group. In prednisone plus cyclophosphamide group cyclophosphamide was given in monthly pulses of $1.0 \mathrm{~g}$ for 6 months, while the prednisone dosage was the same as prednisone group. The two primary end points were a combination of reaching end-stage renal disease (ESRD) or doubling of serum creatinine or death and absolute changes in eGFR (estimated glomerular filtration rate) at 36 months.

Results

Overall, 135 patients were enrolled in our study. There was no significant difference between the two groups at baseline. The two groups had similar primary composite renal outcomes, which occurred in 4 participants (5.97\%) in the prednisone alone group and $5(7.35 \%)$ in the prednisone plus

cyclophosphamide group (hazard ratio, 1.13 [95\% $\mathrm{Cl}, 0.30$ to 4.19$] ; P=0.861$ ). Additionally, no significant difference in eGFR absolute change in three years was found between the two groups $(0.09(-7.42,12.00)$ $\mathrm{ml} / \mathrm{min} / 1.73 \mathrm{~m}^{2}$ in the prednisone alone group vs. $3.24(5.025,9.59) \mathrm{ml} / \mathrm{min} / 1.73 \mathrm{~m}^{2}$ in the prednisone plus cyclophosphamide group; $P=0.578$ ). Proteinuria was reduced similarly in both groups. Treatment with cyclophosphamide led to more adverse events.

\section{Conclusions}

Our study showed that corticosteroids plus cyclophosphamide did not increase the renal benefit of patients with advanced-stage IgA nephropathy but increased adverse effects compared with corticosteroids alone.

Trial registration: ClinicalTrials.gov, NCT01758120. Registered 1 July 2012, https://clinicaltrials.gov/ct2/show/NCT01758120

\section{Background}


IgA nephropathy (IgAN) is the most common primary glomerulonephritis worldwide, especially in China. IgAN is always the primary cause of glomerulonephritis [1,2]. According to the China Kidney Disease Network 2014 Annual Data Report, IgAN accounts for 43.8\% of primary glomerulonephritis in China [3]. Most studies have indicated that $20 \%-30 \%$ of IgAN patients develop end-stage renal disease (ESRD) within ten years [4]. The treatment of IgAN is a continuing challenge.

Renin-angiotensin system inhibitors (RASIs), including angiotensin-converting enzyme inhibitors (ACEls) and angiotensin receptor blockers (ARBs), are well-recognized treatments for IgAN and have been reported to attenuate proteinuria and slow the progression of chronic renal insufficiency [5-7]. However, IgAN is an autoimmune kidney disease, and RASI could not address the immune disorders in IgAN. In the 'multihit' hypothesis, immune disorders involve the production of galactose-deficient 0-glycan IgA1 (Gd-lgA1) by defective mucosal immune responses, specific antiglycan autoantibodies to Gd-IgA1, the formation of nephritogenic immune complexes, mesangial cell activation by kidney immune complex deposition and inflammatory cell aggregation induced by local cytokines and chemokines [8]. Therefore, in theory, glucocorticoids and immunosuppressants could inhibit the production of Gd-IgA1 and specific antiglycan autoantibodies to $\mathrm{Gd}-\mathrm{IgA} 1$, reduce the formation of nephritogenic immune complexes, attenuate local kidney inflammation and alleviate kidney injury. In early clinical studies, glucocorticoids alone or glucocorticoids plus immunosuppressants reduced proteinuria and improved renal function [9-11]. However, a randomized controlled trial, the STOP-IgA study, found that immunosuppressive therapy did not improve the outcome of IgAN $[12,13]$. Although the recent TESTING randomized clinical trial showed a potential renal benefit of oral glucocorticoids, this trial was discontinued because of excess serious adverse events in the glucocorticoid group [14]. The 2012 KDIGO guidelines suggested that patients with persistent proteinuria greater than $1 \mathrm{~g} / \mathrm{d}$, despite 3-6 months of optimized supportive care (including ACE-I or ARB use and blood pressure control) and GFR $>50 \mathrm{ml} / \mathrm{min}$ per $1.73 \mathrm{~m}^{2}$, receive a 6 -month course of corticosteroid therapy. Glucocorticoids plus immunosuppressants were not recommended unless there was crescentic IgAN with rapidly deteriorating kidney function.

However, there were some limitations in these previous studies. First, although a previous study showed that glucocorticoids plus cyclophosphamide (CTX) reduce proteinuria and improve renal function [11], whether CTX has an additional protective effect compared to glucocorticoids alone is also unclear. Second, most studies included only patients with proteinuria greater than $0.75-1.0 \mathrm{~g} / \mathrm{d}[12,14]$. Renal insufficiency has been proven to be an independent risk factor for progression to ESRD in IgAN. The IgAN patients with renal insufficiency and small quantities of proteinuria also had a high risk of progression to ESRD. Whether these patients would benefit from immunosuppressants is unknown. Therefore, we conducted a randomized controlled trial (Treatment of Prednisone Plus Cyclophosphamide in Patients with Advanced-stage IgA Nephropathy, TOPplus-IgAN) that included patients with renal insufficiency regardless of proteinuria level to investigate whether glucocorticoids plus cyclophosphamide have an additional protective effect compared to glucocorticoids alone.

\section{Methods}




\section{Study population}

This study has been registered in ClinicalTrials.gov in 1/1/2013 (NCT01758120). From January 2013 through October 2016, patients with newly diagnosed IgA nephropathy in Guangdong Provincial People's Hospital in one year were screened. The inclusion criteria were a histological diagnosis of $\lg \mathrm{A}$ nephropathy, age 18-70 years and elevated plasma creatinine concentrations (1.3-3.0 mg/dl in males and $1.0-3.0 \mathrm{mg} / \mathrm{dl}$ in females) regardless of proteinuria level. The exclusion criteria were as follows: 1 ) diabetes; 2) contraindications for the treatment of prednisone and/or cyclophosphamide, including but not limited to current infection, neutropenia, thrombocytopenia and abnormal liver function; 3 ) any treatment with steroids or immunosuppressive drugs prior to this study; and 4) acute deterioration of renal function (including those of glomerular origin). The Ethics Research Committee at Guangdong Provincial People's Hospital approved the study. The study was conducted in accordance with the principles contained in the Declaration of Helsinki and the relevant guidelines of Ethics Research Committee at Guangdong Provincial People's Hospital. Written informed consent was obtained from all participants.

\section{Study design}

We conducted a prospective, open-label, randomized, controlled clinical trial. Once the patients with newly diagnosed IgA nephropathy were enrolled in the trial, they were randomly assigned 1:1 to the prednisone alone group or prednisone plus cyclophosphamide group according to the random numbers generated by an independent statistician (odd numbers were assigned to the prednisone alone group, and even numbers were assigned to the prednisone plus CTX group). No run-in phase with ACEI/ARB was designed in this trial because proteinuria level was not involved in the entry criteria. Patients with hypertension (systolic blood pressure $\geq 140 \mathrm{~mm} \mathrm{Hg}$ or diastolic blood pressure $\geq 90 \mathrm{~mm} \mathrm{Hg}$ ) or proteinuria $\geq 500$ $\mathrm{mg} / 24 \mathrm{~h}$ could be treated with RAS blockers at the initiation of the trial, but newly added RAS blockers or increased RAS blocker dosages were prohibited from 1 month. Additional use of calcium channel blockers, $\beta$-blockers, a-blockers and diuretics was allowed to control blood pressure targeting 140/90 $\mathrm{mmHg}$.

In the prednisone alone group, the daily dosage of oral prednisone was initiated at $0.5 \mathrm{mg} / \mathrm{kg} / \mathrm{d}$ taken every morning for 2 months and then tapered by $20 \%$ each month for the next 4 months. In the prednisone plus CTX group, CTX was given in monthly pulses of $1.0 \mathrm{~g}$ in intravenous infusion for 6 months, while the prednisone dosage was the same as that in the prednisone group. In both groups, prednisone treatment was stopped at 6 months. Other immunosuppressants, including but not limited to leflunomide, cyclosporine A, cyclophosphamide, tacrolimus, and methotrexate, were prohibited.

Patients were followed up for an additional 30 months. Patient visits were scheduled monthly during the first 6 months and then every three months. At each of these follow-ups, their clinical and laboratory characteristics were recorded, and the side effects of drugs were evaluated.

\section{Renal biopsy evaluation}


Renal biopsies were scored according to the Oxford Classification of IgAN 2016: mesangial hypercellularity, M0/M1 (< or equal to >50\% of glomeruli with >4 mesangial cells/area); endocapillary hypercellularity, E0/E1 (present/absent); segmental glomerulosclerosis, S0/S1 (present/absent); tubular atrophy/interstitial fibrosis, T0/T1/T2 (<25\%, 25-50\%, >50\%); cellular and/or fibrocellular crescents, $\mathrm{C} 0 / \mathrm{C} 1 / \mathrm{C} 2$ (no crescents, crescent in at least 1 glomerulus but less than $25 \%$ of glomeruli, crescents in at least $25 \%$ of glomeruli) [15].

\section{Study end points}

The two primary end points were a combination of reaching ESRD or doubling serum creatinine or death and absolute changes in eGFR. The secondary end point was the absolute changes in proteinuria in 36 months and complete proteinuria remission of patients with urinary protein excretion $>1.0 \mathrm{~g} / \mathrm{d}$ in 36 months (defined as proteinuria with urinary protein excretion $<0.2 \mathrm{~g} / \mathrm{d}$ and stable renal function with a decrease in the eGFR of $<5 \mathrm{ml}$ per minute per $1.73 \mathrm{~m}^{2}$ from the baseline eGFR at the end of the trial phase).

\section{Statistical analysis}

Because no head-to-head studies compared renal survival between the prednisone group and prednisone plus CTX group, we respectively compared renal survival between the prednisone/prednisone plus CTX and conservative treatment groups ${ }^{9,11}$. We estimated an increase of $16 \%$ in renal survival in the prednisone plus CTX group compared with the prednisone alone group. We calculated that a minimum sample size of 67 patients per group (including a 10\% dropout adaptation) would give the study $80 \%$ power at a two-sided significance level of $5 \%$ to detect rates of reaching end-stage renal disease (ESRD) or doubling of serum creatinine.

Continuous variables are presented as the means \pm standard deviation or medians with interquartile range (IQR) if not normally distributed and were analyzed by the t test or Mann-Whitney U test as appropriate. Categorical variables are described as the numbers and proportions. A $c^{2}$ test, Fisher's exact method, or McNemar's exact test was used to analyze categorical variables.

The primary end point analysis was performed using both intention-to-treat (ITT) and per-protocol (PP) approaches. The second end point analysis was only performed with the PP approach. Subgroup analyses were performed to investigate the interaction of clinical and pathological features with therapy. The safety analysis included all randomly assigned patients who received at least 1 dose of study medication.

Three-year renal survival curves were generated using the Kaplan-Meier method, and curves were compared with the log-rank test. Univariate and multivariate Cox proportional regression analyses were fitted to the data of the primary end points. 
The significant changes in eGFR and daily urinary protein excretion were explored by repeated-measures ANOVA. Bonferroni-corrected post hoc pairwise comparisons were performed when significant main effects were found.

All probability values are two-tailed, and statistical significance was defined as $P<0.05$.

\section{Results}

\section{Study participants}

From January 2013 through October 2016, 696 patients were newly diagnosed with IgA nephropathy in Guangdong Provincial People's Hospital. In total, 362 patients met all inclusion criteria, and 234 were excluded; 15 patients were complicated with diabetes mellitus, 16 patients had immunosuppressor contraindications, and 203 patients declined to participate in clinical studies. Seven patients newly diagnosed with IgA nephropathy in other hospitals met the inclusion criteria. Eventually, 135 patients were enrolled in our study (Figure 1).

Of the 135 patients enrolled, 67 were randomly assigned to the prednisone alone group, and 68 were assigned to the prednisone plus cyclophosphamide group. The baseline demographics, clinical characteristics, and pathologic features of the patients are shown in Table 1. One patient in the prednisone alone group and three patients in the prednisone plus cyclophosphamide group accepted azathioprine as maintenance therapy after 6 months of prednisone or cyclophosphamide treatments. Fourteen patients in the prednisone alone group and 8 patients in the prednisone plus cyclophosphamide group dropped out from our study.

\section{Primary end points}

The primary composite renal outcome occurred in 4 participants (5.97\%) in the prednisone alone group and $5(7.35 \%)$ in the prednisone plus cyclophosphamide group (hazard ratio, 1.13 [95\% $\mathrm{Cl}, 0.30$ to 4.19]; $\mathrm{P}$ $=0.86)$ (Table 2, Figure 2), including $3(2.9 \%)$ and 4 (7.9\%) participants, respectively, reaching ESRD ( $\mathrm{P}=$ 1.00). The per-protocol analysis also showed that the two groups have similar primary composite renal outcomes (Table 2, Figure 2). Although no significant difference in eGFR absolute change in three years was found between the two groups (Table 2), the eGFR of both groups in the third month increased from baseline, peaked at the sixth month and then decreased. At the end of our study, the eGFR of both groups was not lower than baseline (Figure 3 ). We also analyzed relatively complete 24-hour urinary creatinine data of 105 patients. The change in 24-hour urinary creatinine at follow-up also showed a similar trend with eGFR, although there were no significant differences in the time effect (Figure 4).

We further performed Cox proportional regression analyses to investigate the factors of primary composite renal outcome. Sex and baseline eGFR, E and T in the Oxford Classification were associated with renal survival in univariate analyses. We respectively included pathological or clinical factors as well 
as sex, different immunosuppressive therapy groups, hypertension and RASI, which may affect IgA nephropathy outcomes based on previous studies for multivariate analyses in the two models. The combined use of CTX had no impact on the primary composite renal outcome in either model. T in the Oxford Classification and lower eGFR were independent risk factors for primary composite renal outcome (Table 3).

\section{Subgroup analyses}

A subgroup analysis was performed for eGFR change with the use of the ITT analysis set. In patients with crescents, prednisone plus cyclophosphamide did not slow CKD progression compared with the prednisone alone group. There was no difference in the eGFR change trend between the two therapy groups in each proteinuria level subgroup (Figure 5). At the end of follow-up, the eGFR of both groups was similar to baseline whether with crescents or high-grade proteinuria.

\section{Secondary end points}

Proteinuria was significantly reduced in both groups (Figure 6). However, no significant differences were observed between the prednisone alone group and the prednisone plus CTX group at the end of the trial with respect to the mean absolute changes in proteinuria (Figure 6, Table 2). Proteinuria remission of patients with baseline proteinuria greater than $1 \mathrm{~g} / 24 \mathrm{~h}$ was similar in each group at the end of the trial phase (Table 2).

\section{Adverse events}

More adverse events were observed in the prednisone plus CTX group $(10.45 \%$ vs. $26.47 \%, p=0.025)$ (Table 4). The adverse effects of prednisone plus CTX on menopause, gastrointestinal reaction and hair loss were apparent. The numbers of serious adverse events were similar in each group. No deaths occurred in either treatment group.

\section{Discussion}

Although previous research indicated that glucocorticoids plus immunosuppressants could reduce proteinuria and improve renal function [11,16], no RCT compared the effect of glucocorticoids plus CTX on IgA nephropathy compared with glucocorticoids alone. Therefore, the independent protective effect of CTX on IgA nephropathy remains unclear. In the current study, we found that the addition of CTX therapy to glucocorticoids in patients with IgA nephropathy do not improve renal outcomes. Some clinicians regard crescents in renal biopsy as indicators of the combined use of glucocorticoids and immunosuppressants [17]. Nearly 50\% of patients in our study had more than 1 crescent, and glucocorticoid plus CTX failed to improve the renal outcomes of these patients compared with glucocorticoid alone. More patients in the prednisone plus CTX group than in the prednisone alone group had adverse effects. Our research results provided further evidence to support the 2012 KDIGO clinical practice guidelines on glomerular diseases, which suggested not treating IgA nephropathy patients with 
corticosteroids combined with cyclophosphamide or azathioprine unless crescentic IgA nephropathy with rapidly deteriorating kidney function was present [18]. However, the independent therapeutic benefits of CTX need to be explored in longer follow-ups. Additionally, the incidence of primary outcomes was lower than expected, and the dropout rate was higher than expected. This could have limited the detection of CTX-independent therapy benefits.

The STOP-IgA study and its ten-year follow-up found that glucocorticoids alone or plus CTX did not improve the renal outcomes of IgA nephropathy[12,13]. However, even the rate of eGFR loss among patients in the supportive therapy group was approximately $-1.6 \mathrm{~mL} / \mathrm{min} / 1.73 \mathrm{~m}^{2}$ per year, which is close to that of normal people, and additional treatment has difficulty reducing the rate of eGFR loss furtherly. In the TESTING study, the rate of eGFR loss among patients in the supportive therapy group was -6.95 $\mathrm{mL} / \mathrm{min} / 1.73 \mathrm{~m}^{2}$ per year, and corticosteroid decreased the rate of eGFR loss to $-1.79 \mathrm{~mL} / \mathrm{min} / 1.73 \mathrm{~m}^{2}$ per year [14]. Possible reasons for the difference in results may be the differences in participants' baseline characteristics between STOP-IgA and TESTING; in particular, over $95 \%$ of participants in TESTING were Chinese and had a higher risk of IgA nephropathy progression than the European population [19]. Our study recruited Chinese patients with advanced-stage IgA nephropathy who had a high risk of CKD progression. Although no control group with just supportive care was set, eGFR was not decreased at the end of the trial phase in either immunosuppressive therapy group and even increased in the third month and sixth month. The early increase in eGFR was also observed in the corticosteroid-treated participants in the TESTING study. Because the 24-hour urinary creatinine of corticosteroid-treated participants decreased in the early stage of the TESTING study, some of the eGFR effects may have been due to sarcopenic effects of corticosteroids, leading to reduced creatinine generation. However, in our study, the 24-hour urinary creatinine of each group showed a trend similar to that of eGFR. The different changes in 24-hour urinary creatinine between TESTING and the present study may be due to different inclusion criteria and different dosages of corticosteroids. The results of our study indicated that immunosuppressive therapy may improve the renal function of advanced-stage IgA nephropathy patients. The effect of immunosuppressive therapy on IgA nephropathy patients may have ethnic differences. For example, although Tang et al found that mycophenolate mofetil could reduce proteinuria in Chinese patients with a high risk of IgA nephropathy [20], mycophenolate mofetil had no protective effect on IgA nephropathy patients in Europe and America [21,22]. The present study (31.08\% in 36 months) and the TESTING study (52.2\% in 24 months) also showed a higher complete proteinuria remission rate than STOP-IgA (17\% in 36 months), which may mean that Chinese IgA nephropathy patients had a better response to glucocorticoid therapy. Combined with the results of the TESTING study and our study, we think that glucocorticoid therapy could at least improve disease progression in Chinese patients with a high risk of IgA nephropathy progression.

Although glucocorticoids have a protective effect on IgA nephropathy, the adverse effects of immunosuppressive therapy should be considered when treatment decisions for IgA nephropathy are made. The TESTING study was discontinued because of excess serious adverse events in the corticosteroid group [14]. The proportion of serious adverse events for each group in our study was relatively low because of the low dose of corticosteroids, whereas patients in each group had similar renal 
outcomes compared with the TESTING study. These results indicated that IgA nephropathy patients do not benefit from excessive immunosuppressive therapy, either full dose corticosteroids or combined use of CTX. A half dose of corticosteroids $(0.5 \mathrm{mg} / \mathrm{kg} / \mathrm{d}$ for prednisone or $0.4 \mathrm{mg} / \mathrm{kg} / \mathrm{d}$ for methylprednisolone) may be a good choice for patients with IgA nephropathy in whom immunosuppression is considered. This suggestion may be proven by the ongoing TESTING Low Dose Study (NCT01560052).

Furthermore, patients with elevated serum creatinine but low proteinuria were included in the present study. Even in patients with proteinuria less than $1 \mathrm{~g} / \mathrm{d}$, we found that eGFR in both groups is not clearly decreased; rather, it increased without statistical significance at the end of study. This result demonstrated that patients with insufficient renal function and low proteinuria may also benefit from immunosuppressive therapy. Previously, few researchers included patients with insufficient renal function and low proteinuria. Ballardie et al conducted a randomized controlled trial with small sample sizes, including patients with impaired renal function (serum creatinine greater than $130 \mu \mathrm{mol} / \mathrm{L}$ ) regardless of proteinuria level. Their study indicated that treatment with prednisolone and cytotoxic agents could improve renal survival compared with supportive care [11]. Another study included IgA nephropathy patients with serum creatinine higher than $175 \mathrm{mmol} / \mathrm{I}$ and/or an increase in serum creatinine of more than $25 \%$ in the previous three months and did not set entry criteria for proteinuria [23]. They found that prednisolone plus monthly intravenous pulse therapy was able to stop the loss of renal function and decrease proteinuria. However, this study was not a randomized controlled trial and did not analyze the outcomes of patients with low proteinuria. Our study provides further evidence of immunosuppressive therapy for IgA nephropathy with insufficient renal function and low proteinuria.

In our study, renal outcomes were not associated with proteinuria level, which has been proven to be a risk factor for IgA nephropathy progression [4,24]. Two reasons may explain this result. First, all patients in our study received immunosuppressive therapy, which may have attenuated the effect of proteinuria on renal outcomes. Second, the sample size of this trial may have limited the detection of the effect of proteinuria.

\section{Conclusion}

In conclusion, the present study showed that corticosteroids plus CTX did not improve outcomes of patients with advanced-stage IgA nephropathy but increased adverse effects compared with corticosteroids alone.

\section{Declarations}

\section{Ethics approval and consent to participate}

All the participants signed a written informed consent form for participation in this study. Ethics approval was obtained from the Medial Ethics Committee of Guangdong Provincial People's Hospital (No. GDREC2012103H). The study was conducted in accordance with the principles contained in the 
Declaration of Helsinki and the relevant guidelines of Ethics Research Committee at Guangdong Provincial People's Hospital.

\section{Consent for publication}

Not applicable.

\section{Availability of data and materials}

Original data was stored in a standard EXCEL database and can be requested via the corresponding author. xinlingliang_ggh@163.com.

\section{Competing interests}

The authors have no conflict of interest to declare.

\section{Funding sources}

This work was supported by the Guangdong-Hong Kong Joint Laboratory on Immunological and Genetic Kidney Diseases (2019B121205005), Guangdong Province Medical Science and Technology Research Foundation (2015124111013937) and Science and Technology Program of Guangzhou (2012Y2-00028).

\section{Authors' contributions}

Research idea, study design $₫ X$. L.L; participants' enrollment\Z.L.F., W.D., W.S., Z.M.Y., S.X.L., W.J.W.; participant follow-up: Z.L.F, W,D., Y.H.C, L.Z., R.Z.L, L.X.X, J.C.M., H.B.L.; database management: T.Z., W.D., Z.X.; ethics and regulatory document preparation: Z.L.F; pathological analysis: Y.M.T., Z.L.L; data analysis/interpretation and statistical analysis: L.S., T.Z.; supervision or mentorship: X.L.L., W.D.; Each author contributed important intellectual content during manuscript drafting or revision and accepts accountability for the overall work by ensuring that questions pertaining to the accuracy or integrity of any portion of the work are appropriately investigated and resolved.

\section{Acknowledgments}

The TOPplus IgAN study was designed by Professor Zhang Bin (Guangdong Provincial People's Hospital, Guangdong Academy of Medical Sciences), and the early stages of this clinical trial was also conducted by Professor Zhang Bin. Unfortunately, Professor Zhang passed away from pancreatic cancer. This article will express our grief and admiration for him. Professor Zhang will always be the 'Top One' in our hearts.

\section{References}

1. Schena FP, Nistor I. Epidemiology of IgA Nephropathy: A Global Perspective. Semin Nephrol. 2018;38:435-442. 
2. Hou JH, Zhu HX, Zhou ML, Le WB, Zeng CH, Liang SS, et al. Changes in the Spectrum of Kidney Diseases: An Analysis of 40,759 Biopsy-Proven Cases from 2003 to 2014 in China. Kidney Dis (Basel). 2018;4:10-19.

3. Zhang L, Wang H, Long J, Shi Y, Bai K, Jiang W, et al. China Kidney Disease Network (CK-NET) 2014 Annual Data Report. Am J Kidney Dis. 2017;69(6S2):A4.

4. D Amico G. Natural history of idiopathic IgA nephropathy and factors predictive of disease outcome. Semin Nephrol. 2004;24:179-196.

5. Reid S, Cawthon PM, Craig JC, Samuels JA, Molony DA, Strippoli GF. Non-immunosuppressive treatment for IgA nephropathy. Cochrane Database Syst Rev. 2011;:CD003962.

6. Coppo R, Peruzzi L, Amore A, Piccoli A, Cochat P, Stone R, et al. IgACE: a placebo-controlled, randomized trial of angiotensin-converting enzyme inhibitors in children and young people with IgA nephropathy and moderate proteinuria. J Am Soc Nephrol. 2007;18:1880-1888.

7. Nakamura T, Ushiyama C, Suzuki S, Hara M, Shimada N, Sekizuka K, et al. Effects of angiotensinconverting enzyme inhibitor, angiotensin II receptor antagonist and calcium antagonist on urinary podocytes in patients with IgA nephropathy. Am J Nephrol. 2000;20:373-379.

8. Lai KN, Tang SCW, Schena FP, et al. IgA nephropathy. Nat Rev Dis Primers. 2016;2:16001.

9. Pozzi C, Bolasco PG, Fogazzi GB, Andrulli S, Altieri P, Ponticelli C, et al. Corticosteroids in IgA nephropathy: a randomised controlled trial. Lancet. 1999;353:883-887.

10. Pozzi C, Andrulli S, Del Vecchio L, Melis P, Fogazzi GB, Altieri P, et al. Corticosteroid Effectiveness in IgA Nephropathy: Long-Term Results of a Randomized, Controlled Trial. J Am Soc Nephrol. 2004;15:157163.

11. Ballardie FW, Roberts ISD. Controlled prospective trial of prednisolone and cytotoxics in progressive IgA nephropathy. J Am Soc Nephrol. 2002;13(1):142-148.

12. Rauen T, Eitner F, Fitzner C, Sommerer C, Zeier M, Otte B, et al. Intensive Supportive Care plus Immunosuppression in IgA Nephropathy. N Engl J Med. 2015;373:2225-2236.

13. Rauen T, Wied S, Fitzner C, Eitner F, Sommerer C, Zeier M, et al. After ten years of follow-up, no difference between supportive care plus immunosuppression and supportive care alone in IgA nephropathy. Kidney Int. 2020;98:1044-1052.

14. Lv J, Zhang H, Wong MG, Jardine MJ, Hladunewich M, Jha V, et al. Effect of Oral Methylprednisolone on Clinical Outcomes in Patients With IgA Nephropathy. JAMA. 2017;318:432-442. 
15. Trimarchi H, Barratt J, Cattran DC, Cook HT, Coppo R, Haas M, et al. Oxford Classification of IgA nephropathy 2016: an update from the IgA Nephropathy Classification Working Group. Kidney Int. 2017;91:1014-1021.

16. Hou JH, Le WB, Chen N, Wang WM, Liu ZS, Liu D, et al. Mycophenolate Mofetil Combined With Prednisone Versus Full-Dose Prednisone in IgA Nephropathy With Active Proliferative Lesions: A Randomized Controlled Trial. Am J Kidney Dis. 2017;69:788-795.

17. Tumlin JA, Lohavichan V, Hennigar R. Crescentic, proliferative IgA nephropathy: clinical and histological response to methylprednisolone and intravenous cyclophosphamide. Nephrol Dial Transplant. 2003;18:1321-1329.

18. KDIGO. KDIGO Clinical Practice Guideline for Glomerulonephritis. Kidney Int Suppl.2012;2:139-274.

19. Kiryluk K, Li Y, Sanna-Cherchi S, Rohanizadegan M, Suzuki H, Eitner F, et al. Geographic differences in genetic susceptibility to IgA nephropathy: GWAS replication study and geospatial risk analysis. PLoS Genet. 2012;8(6):e1002765.

20. Tang S, Leung JC, Chan LY, Lui YH, Tang CS, Kan CH, et al. Mycophenolate mofetil alleviates persistent proteinuria in IgA nephropathy. Kidney Int. 2005;68:802-812.

21. Maes BD, Oyen R, Claes K, Evenepoel P, Kuypers D, Vanwalleghem J, et al. Mycophenolate mofetil in IgA nephropathy: Results of a 3-year prospective placebo-controlled randomized study. Kidney Int. 2004;65:1842-1849.

22. Hogg RJ, Bay RC, Jennette JC, Sibley R, Kumar S, Fervenza FC, et al. Randomized Controlled Trial of Mycophenolate Mofetil in Children, Adolescents, and Adults With IgA Nephropathy. Am J Kidney Dis. 2015;66:783-791.

23. Rasche FM, Sailer LC, Czock D, Keller F. Tonsillectomy, high dose immunoglobulins, and cyclophosphamide in progressive IgA-nephropathy. Acta Otolaryngol Suppl. 2004:32-37.

24. Shu D, Xu F, Su Z, Zhang J, Chen C, Zhang J, et al. Risk factors of progressive IgA nephropathy which progress to end stage renal disease within ten years: a case-control study. BMC Nephrol. 2017;18:11.

\section{Tables}

Table1. Baseline Characteristics of Participants 


\begin{tabular}{|c|c|c|c|}
\hline Characteristic & $\begin{array}{l}\text { Prednisone } \\
\text { alone group, } n=67\end{array}$ & $\begin{array}{l}\text { Prednisone plus } \\
\text { cyclophosphamide group, } n=68\end{array}$ & $P$ \\
\hline men, n (\%) & $36(53.7)$ & $41(60.3)$ & 0.489 \\
\hline Age, year & $37.61 \pm 9.80$ & $38.46 \pm 10.57$ & 0.631 \\
\hline Body mass index, $\mathrm{kg} / \mathrm{m}^{2}$ & $23.17 \pm 3.27$ & $22.91 \pm 3.13$ & 0.640 \\
\hline \multicolumn{4}{|l|}{$\mathrm{BP}, \mathrm{mmHg}$} \\
\hline Systolic & $141.01 \pm 19.98$ & $146.65 \pm 25.44$ & 0.155 \\
\hline Diastolic & $90.09 \pm 15.54$ & $87.41 \pm 14.22$ & 0.298 \\
\hline Hypertensive patients, n (\%) & $39(58.21)$ & $31(45.59)$ & 0.166 \\
\hline Serum creatinine, mg/dl & $1.83 \pm 0.54$ & $1.84 \pm 0.52$ & 0.920 \\
\hline eGFR, $\mathrm{ml} / \mathrm{min}$ per $1.73 \mathrm{~m}^{2}$ & $44.87 \pm 15.51$ & $44.85 \pm 14.14$ & 0.995 \\
\hline \multicolumn{4}{|l|}{ eGFR category, n (\%) } \\
\hline$<30.00 \mathrm{ml}$ per $1.73 \mathrm{~m}^{2}$ & $14(20.90)$ & $10(14.71)$ & \multirow[t]{3}{*}{0.571} \\
\hline $\begin{array}{l}30.00-59.99 \mathrm{ml} / \mathrm{min} \text { per } 1.73 \\
\mathrm{~m}^{2}\end{array}$ & $41(61.19)$ & $47(69.18)$ & \\
\hline$\geq 60.00 \mathrm{ml} / \mathrm{min}$ per $1.73 \mathrm{~m}^{2}$ & $12(17.91)$ & $11(16.18)$ & \\
\hline Cholesterol, mmol/L & $5.25 \pm 1.20$ & $5.42 \pm 1.31$ & 0.434 \\
\hline Triglyceride, $\mathrm{mmol} / \mathrm{L}$ & $2.05(1.28,2.50)$ & $1.60(1.11,2.27)$ & 0.132 \\
\hline Anemia, n (\%) & $21(31.34)$ & $27(39.71)$ & 0.370 \\
\hline Serum albumin, $\mathrm{g} / \mathrm{L}$ & $34.42 \pm 5.23$ & $34.93 \pm 4.36$ & 0.539 \\
\hline $\begin{array}{l}\text { Urinary protein excretion, } \\
\text { g/d }\end{array}$ & $1.55(0.75,2.57)$ & $1.43(0.65,2.28)$ & 0.798 \\
\hline \multicolumn{4}{|l|}{$\begin{array}{l}\text { Urinary protein } \\
\text { excretion category, n (\%) }\end{array}$} \\
\hline$<0.50 \mathrm{~g} / 24 \mathrm{~h}$ & $12(17.91)$ & $11(16.18)$ & \multirow[t]{4}{*}{0.920} \\
\hline $0.50-0.99 \mathrm{~g} / 24 \mathrm{~h}$ & $10(14.93)$ & $12(17.65)$ & \\
\hline $0.99-3.49 \mathrm{~g} / 24 \mathrm{~h}$ & $37(55.22)$ & $35(51.57)$ & \\
\hline$\geq 3.49 \mathrm{~g} / 24 \mathrm{~h}$ & $8(11.94)$ & $10(14.71)$ & \\
\hline Smoker, n (\%) & $4(5.97)$ & $5(7.35)$ & 1.000 \\
\hline
\end{tabular}




\begin{tabular}{|llll|}
\hline ACEI or ARB, n (\%) & $45(67.16)$ & $48(70.59)$ & 0.713 \\
\hline Spironolactone, n (\%) & $3(4.48)$ & $2(2.94)$ & 0.987 \\
\hline Statins, n (\%) & $18(26.87)$ & $13(19.12)$ & 0.312 \\
\hline Oxford histological score & & & \\
\hline M1, n (\%) & $32(53.33)$ & $34(54.84)$ & 0.868 \\
\hline E1, n (\%) & $9(15.00)$ & $15(24.59)$ & 0.186 \\
\hline S1, n (\%) & $31(51.67)$ & $38(59.38)$ & 0.388 \\
\hline T0, n (\%) & $20(33.33)$ & $20(33.33)$ & \\
\hline T1, n (\%) & $26(43.33)$ & $26(43.33)$ & \\
\hline T2, n (\%) & $14(23.33)$ & $14(23.33)$ & 0.410 \\
\hline C0, n (\%) & $32(51.61)$ & $40(59.7)$ & \\
\hline C1, n (\%) & $29(46.77)$ & $25(37.31)$ & \\
\hline C2, n (\%) & $1(1.61)$ & $2(2.99)$ & \\
\hline
\end{tabular}

Values for categorical variables are given as counts (percentages), and values for continuous variables are given as the means \pm standard deviation or medians (interquartile range). There was no significant difference in baseline characteristics between the two groups. eGFR, estimated glomerular filtration rate; $\mathrm{BP}$, blood pressure. ACEls, angiotensin-converting enzyme inhibitors; ARBs, angiotensin receptor blockers.

Table2. Effects of Different Treatments on Prespecified Primary and Secondary Outcomes 


\begin{tabular}{|c|c|c|c|}
\hline Outcomes & $\begin{array}{l}\text { Prednisone } \\
\text { alone group }\end{array}$ & $\begin{array}{l}\text { Prednisone plus } \\
\text { cyclophosphamide } \\
\text { group }\end{array}$ & $P$ \\
\hline \multicolumn{4}{|l|}{ Primary Outcomes } \\
\hline \multirow[t]{4}{*}{ ESRD or doubling of serum Creatinine or death } & \multicolumn{3}{|l|}{ ITT } \\
\hline & $4(5.97)$ & $5(7.35)$ & 0.866 \\
\hline & \multicolumn{3}{|l|}{ PP } \\
\hline & $4(7.55)$ & $5(8.33)$ & 0.899 \\
\hline \multirow[t]{4}{*}{ Absolute changes in the eGFR in 36 months } & \multicolumn{3}{|l|}{ ITT } \\
\hline & $\begin{array}{l}0.09(-7.42 \\
12.00)\end{array}$ & $3.24(5.025,9.59)$ & 0.578 \\
\hline & \multicolumn{3}{|l|}{ PP } \\
\hline & $\begin{array}{l}0.04(-8.07 \\
12.07)\end{array}$ & $3.74(-3.51,9.87)$ & 0.285 \\
\hline \multicolumn{4}{|l|}{ Secondary Outcomes } \\
\hline Absolute changes of proteinuria in 36 months, $\mathrm{g} / \mathrm{d}$ & $\begin{array}{l}-0.59(-1.66, \\
-0.02)\end{array}$ & $-0.63(-1.41,-0.09)$ & 0.818 \\
\hline $\begin{array}{l}\text { Complete proteinuria remission rate of patients } \\
\text { with proteinuria more than } 1.0 \mathrm{~g} / \mathrm{d} \text { in } 36 \text { months }\end{array}$ & $\begin{array}{l}11 / 34 \\
(32.35 \%)\end{array}$ & $12 / 40(30.00 \%)$ & 0.827 \\
\hline
\end{tabular}

ESRD, end-stage renal disease; eGFR, estimated glomerular filtration rate; ITT, intention-to-treat; PP, perprotocol.

Table 3. Effects of Different Therapies on Primary Composite Outcome by Multivariate Regression. 


\begin{tabular}{|c|c|c|c|c|c|c|}
\hline \multirow[t]{3}{*}{ Variable } & \multirow{2}{*}{\multicolumn{2}{|c|}{ Univariate }} & \multicolumn{4}{|l|}{ Multivariate } \\
\hline & & & \multicolumn{2}{|l|}{ Model 1} & \multicolumn{2}{|l|}{ Model 2} \\
\hline & $\mathrm{HR}(95 \% \mathrm{Cl})$ & $P$ value & $\mathrm{HR}(95 \% \mathrm{Cl})$ & $P$ value & $\mathrm{HR}(95 \% \mathrm{Cl})$ & $P$ value \\
\hline $\begin{array}{l}\text { Prednisone plus } \\
\text { cyclophosphamide }\end{array}$ & $\begin{array}{l}1.119(0.300- \\
4.170)\end{array}$ & 0.866 & $\begin{array}{l}0.454(0.090- \\
2.288)\end{array}$ & 0.339 & $\begin{array}{l}1.225(0.295- \\
5.084)\end{array}$ & 0.780 \\
\hline Male sex & $\begin{array}{l}0.208(0.043- \\
1.000)\end{array}$ & 0.050 & $\begin{array}{l}0.249(0.047- \\
1.273)\end{array}$ & 0.101 & $\begin{array}{l}0.396(0.073- \\
2.151)\end{array}$ & 0.283 \\
\hline $\begin{array}{l}\text { eGFR (per } \\
\mathrm{ml} / \mathrm{min} / 17.3 \mathrm{~m}^{2} \text { ) }\end{array}$ & $\begin{array}{l}0.902(0.842- \\
0.968)\end{array}$ & 0.004 & NA & NA & $\begin{array}{l}0.896(0.822- \\
0.976)\end{array}$ & 0.012 \\
\hline Proteinuria $(\mathrm{g} / \mathrm{d})$ & $\begin{array}{l}1.105(0.956- \\
1.278)\end{array}$ & 0.177 & NA & NA & $\begin{array}{l}1.114(0.887- \\
1.399)\end{array}$ & 0.351 \\
\hline \multicolumn{7}{|l|}{$\mathrm{T}$} \\
\hline $\mathrm{T} 0$ or $\mathrm{T} 1$ & Reference & & Reference & & NA & NA \\
\hline T2 & $\begin{array}{l}12.116(2.439- \\
60.186)\end{array}$ & 0.002 & $\begin{array}{l}11.203(2.115- \\
59.336)\end{array}$ & 0.005 & NA & NA \\
\hline \multicolumn{7}{|l|}{$E$} \\
\hline EO & Reference & & Reference & & NA & NA \\
\hline E1 & $\begin{array}{l}4.424(1.106- \\
17.689)\end{array}$ & 0.035 & $\begin{array}{l}5.071(0.892- \\
28.835)\end{array}$ & 0.067 & NA & NA \\
\hline Hypertension & $\begin{array}{l}1.317(0.354- \\
4.906)\end{array}$ & 0.680 & $\begin{array}{l}1.779(0.353- \\
8.956)\end{array}$ & 0.485 & $\begin{array}{l}0.786(0.191- \\
3.236)\end{array}$ & 0.739 \\
\hline Using ACEI or ARB & $\begin{array}{l}0.844(0.211- \\
3.375)\end{array}$ & 0.810 & $\begin{array}{l}3.311(0.574- \\
19.082)\end{array}$ & 0.180 & $\begin{array}{l}2.330(0.496- \\
10.938)\end{array}$ & 0.284 \\
\hline
\end{tabular}

Model 1 adjusted for pathology, sex, hypertension and RASI. Model 2 adjusted for proteinuria, eGFR, sex, hypertension and RASI.

Table 4. Adverse Events and Serious Adverse Events during the Trial 


\begin{tabular}{|c|c|c|c|}
\hline Adverse Events & $\begin{array}{l}\text { Prednisone } \\
\text { alone group } \rrbracket \\
n=67\end{array}$ & $\begin{array}{l}\text { Prednisone plus } \\
\text { cyclophosphamide group } ₫ n=68\end{array}$ & $P$ \\
\hline Total Adverse Events & 7 & 19 & 0.015 \\
\hline Sleep disorder & 1 & 0 & 0.496 \\
\hline Hypokalemia & 1 & 0 & 0.496 \\
\hline Hyperkalemia & 0 & 1 & 1.000 \\
\hline Nerve damage & 0 & 1 & 1.000 \\
\hline Cerebral hemorrhage & 1 & 0 & 0.496 \\
\hline Gynecomastia & 0 & 1 & 1.000 \\
\hline $\begin{array}{l}\text { Gastrointestinal } \\
\text { discomfort }\end{array}$ & 0 & 3 & 0.244 \\
\hline Gastrointestinal bleeding & 1 & 1 & 1.000 \\
\hline Hair loss & 0 & 3 & 0.244 \\
\hline Menopause & 0 & 3 & 0.244 \\
\hline Steroid diabetes & 0 & 1 & 1.000 \\
\hline Anemia & 0 & 1 & 1.000 \\
\hline Infection & 3 & 4 & 1.000 \\
\hline $\begin{array}{l}\text { Upper respiratory } \\
\text { infection }\end{array}$ & 1 & 0 & 0.496 \\
\hline $\begin{array}{l}\text { Infection of skin and } \\
\text { knee joint }\end{array}$ & 0 & 2 & 0.496 \\
\hline Urinary tract infection & 1 & 0 & 0.496 \\
\hline Pneumonia & 0 & 2 & 0.496 \\
\hline $\begin{array}{l}\text { Acute gangrenous } \\
\text { appendicitis }\end{array}$ & 1 & 0 & 0.496 \\
\hline $\begin{array}{l}\text { Total Serious Adverse } \\
\text { Events }\end{array}$ & 2 & 2 & 1.000 \\
\hline Pneumonia & 0 & 2 & 0.496 \\
\hline Cerebral hemorrhage & 1 & 0 & 0.496 \\
\hline $\begin{array}{l}\text { Acute gangrenous } \\
\text { appendicitis }\end{array}$ & 1 & 0 & 0.496 \\
\hline
\end{tabular}




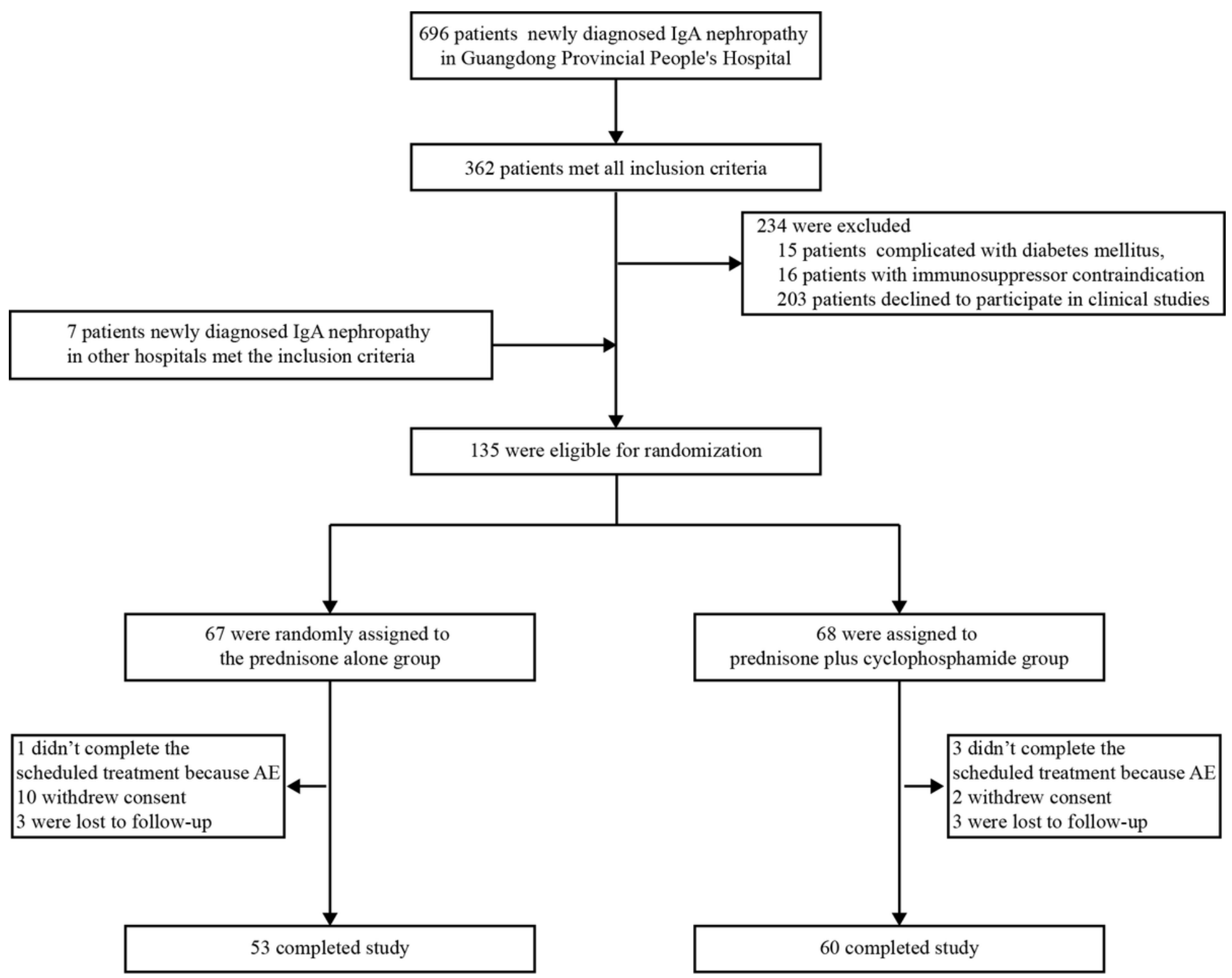

\section{Figure 1}

Eligibility, Enrollment, and Randomization. In total, 696 patients were newly diagnosed with IgA nephropathy in Guangdong Provincial People's Hospital from June 2012 through October 2016. Among 362 patients who met all inclusion criteria, 234 were excluded because of diabetes mellitus, immunosuppressor contraindications and rejection to participate in this trial. Seven patients newly diagnosed with IgA nephropathy in other hospitals met the inclusion criteria. Eventually, 135 patients participated in this study and were randomly assigned to either the prednisone alone group or the prednisone plus cyclophosphamide group. Fourteen participants in the prednisone alone group and 8 participants in the prednisone plus cyclophosphamide group did not complete the study. AE, adverse effect. 
A

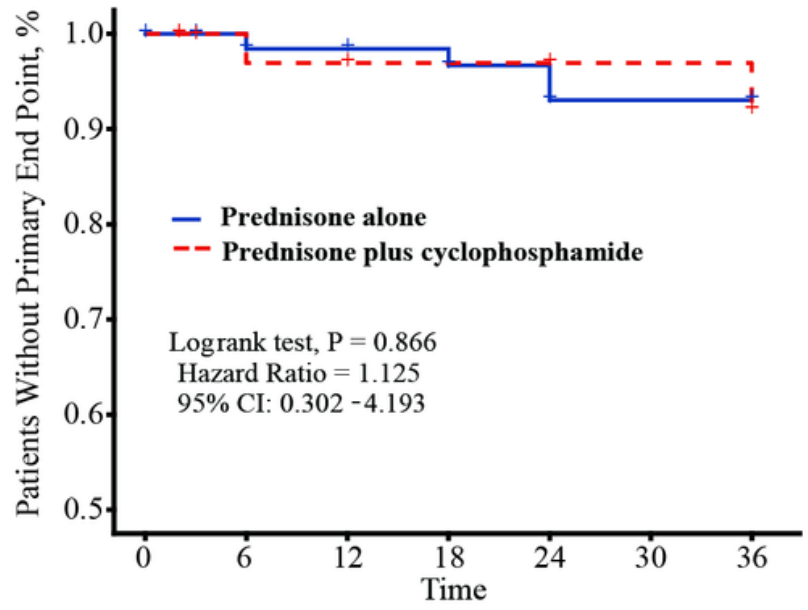

Number at risk by time

\begin{tabular}{|c|c|c|c|c|c|c|c|}
\hline Prednisone alone & 67 & 63 & 59 & 57 & 53 & 49 & 49 \\
\hline Prednisone plus & 68 & 65 & 63 & 62 & 62 & 58 & 58 \\
\hline
\end{tabular}

B

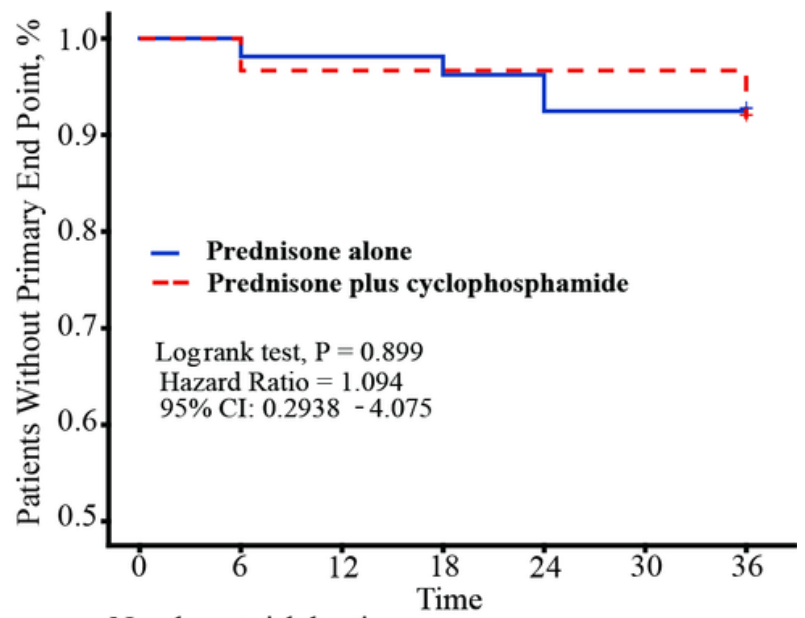

Number at risk by time

Figure 2

Kaplan-Meier analysis for first primary composite outcome of end-stage renal disease or doubling of serum creatinine or death by treatment group. A. intention-to-treat. Hazard ratio $=1.125[95 \% \mathrm{Cl}, 0.302-$ 4.193]; $P=0.866$. B. per-protocol approach. Hazard ratio=1.094 [95\% Cl, 0.294-4.075]; $P=0.899$.

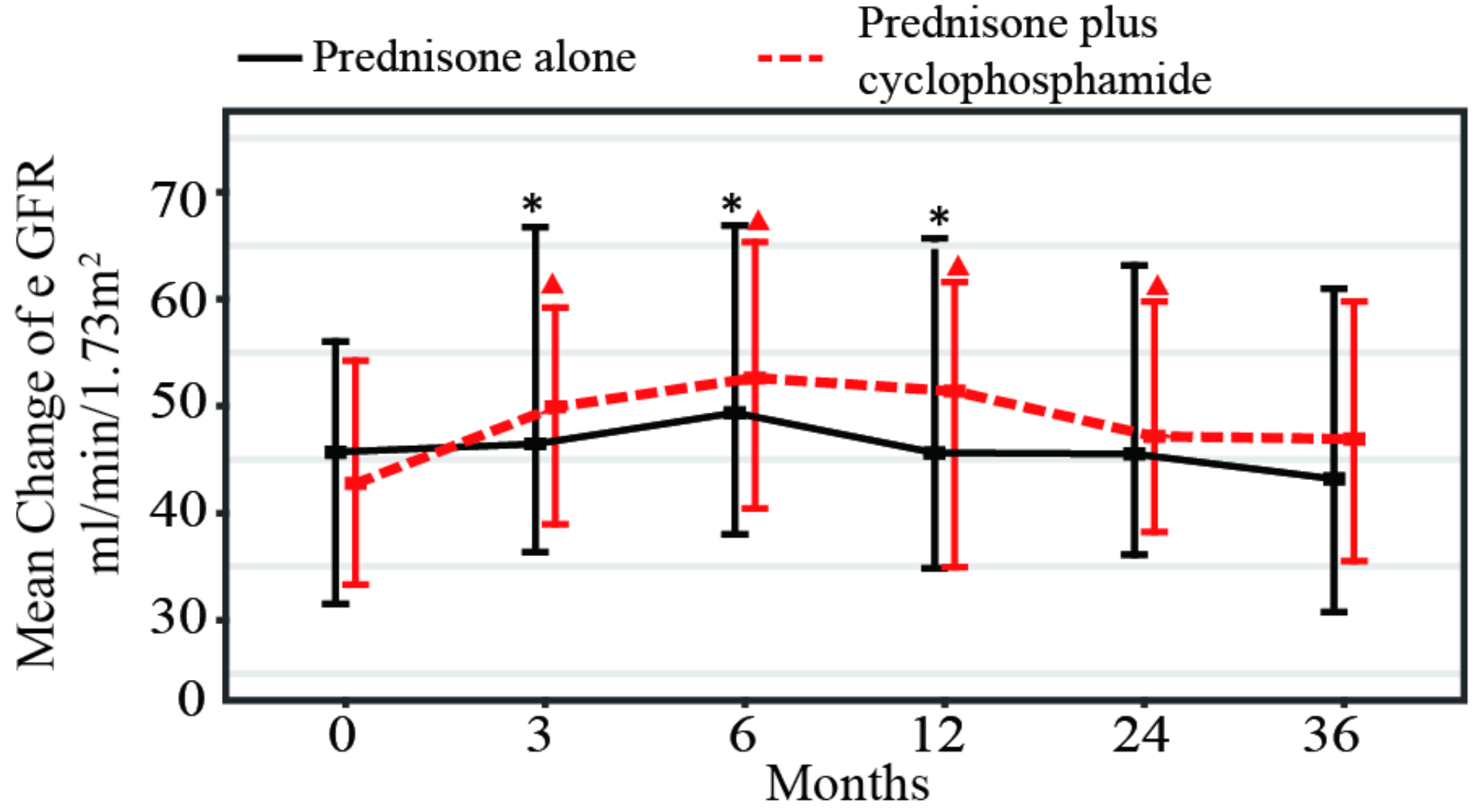

Figure 3 
Effect of different therapies on eGFR. The two groups had similar absolute eGFR changes. The eGFR of each group increased from baseline in the third month, peaked at the sixth month and then decreased.

$\Delta$ Significant changes in the prednisone plus cyclophosphamide group compared to the baseline level $(\mathrm{P}<$ 0.05). eGFR, estimated glomerular filtration rate.

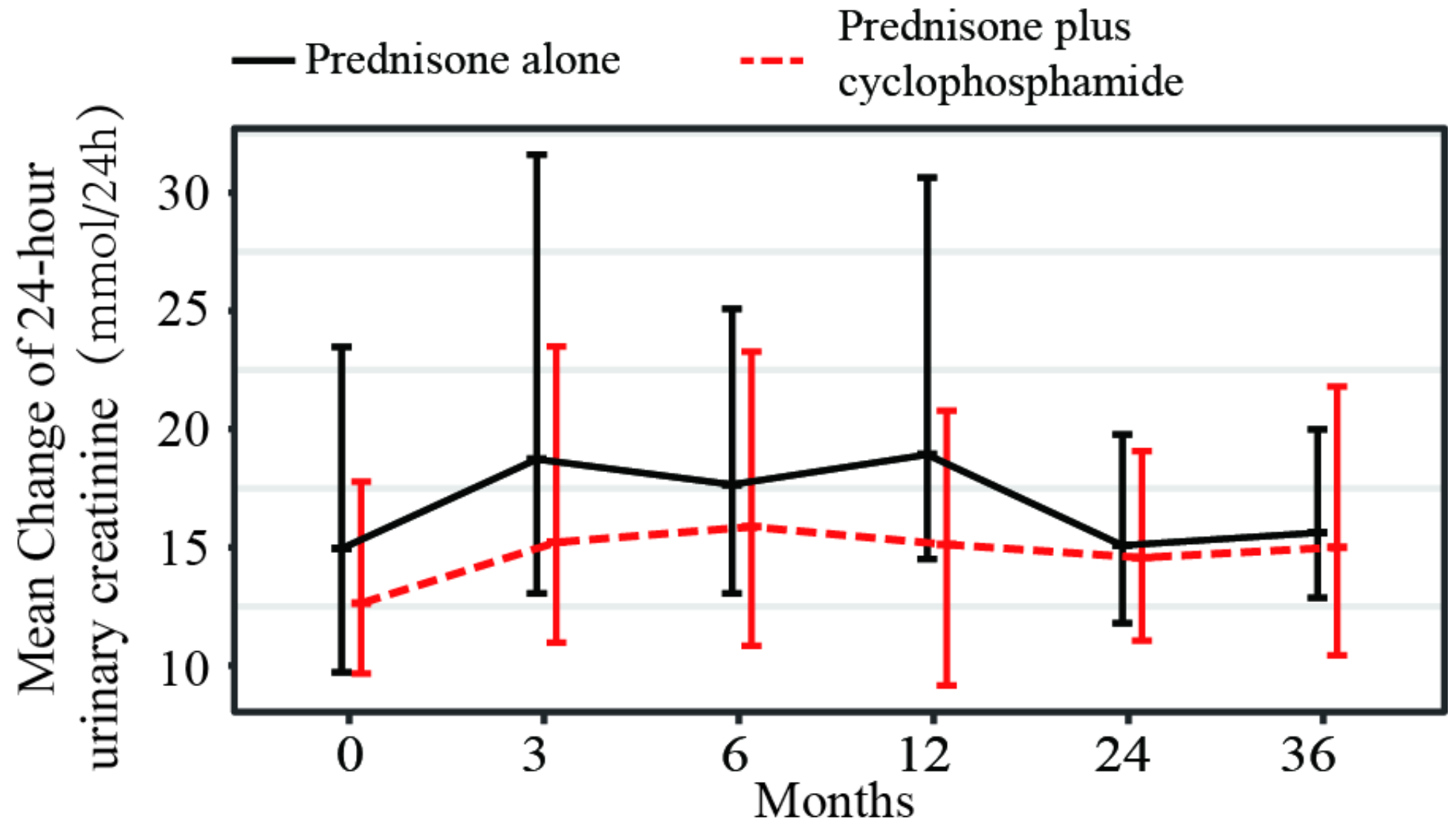

Figure 4

Effect of different therapies on 24-hour urinary creatinine. The eGFR of the two groups had a similar trend of 24-hour urinary creatinine change. No significant differences in the time effect were found in either group. 

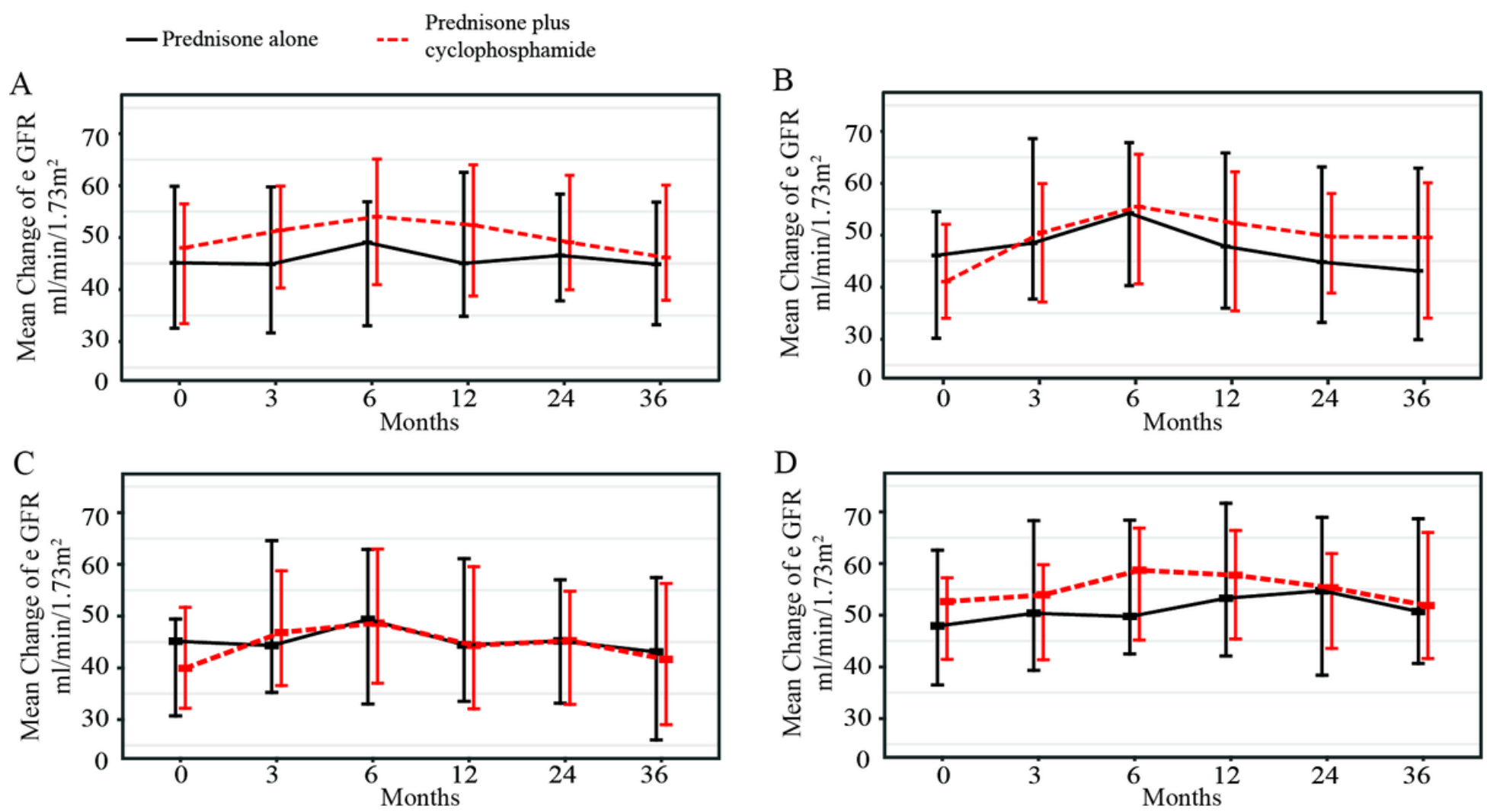

Figure 5

Effect of different therapies on eGFR by subgroup. The two eGFR groups had similar absolute eGFR changes in subgroup analyses. A. Effect of different therapies on eGFR in participants without crescents. B. Effect of different therapies on eGFR in participants with crescents. C. Effect of different therapies on eGFR in participants with proteinuria equal to or greater than $1 \mathrm{~g} / \mathrm{d}$. D. Effect of different therapies on eGFR in participants with proteinuria less than $1 \mathrm{~g} / \mathrm{d}$. eGFR, estimated glomerular filtration rate. 


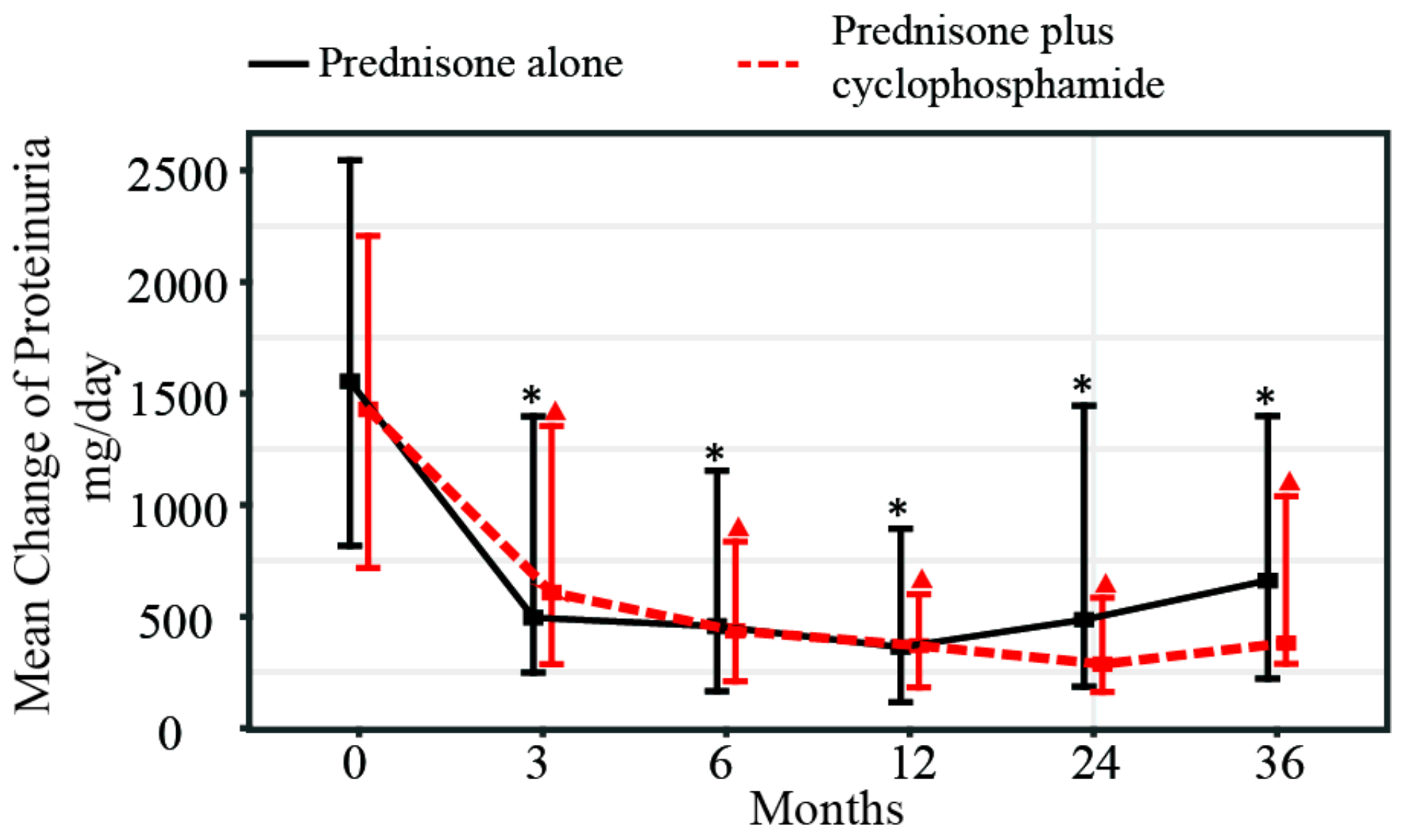

Figure 6

Effect of different therapies on urinary protein in all participants. Both therapy groups had significantly reduced urinary protein. * Significant changes in the prednisone alone group compared to the baseline level $(p<0.05)$. $\Delta$ Significant changes in the prednisone plus cyclophosphamide group compared to the baseline level $(P<0.05)$. 